\title{
Diagnóstico incidental en tiempos de coronavirus: mixoma cardíaco en orejuela izquierda
}

Juan Beteré Reynolds*

Irene Rodríguez Torres*

José David Rodrigo Carbonero**

Pedro Pérez Rodrigo**

Ignacio Díaz de Lezcano***

* Servicio de Cardiología. Hospital Universitario de Cruces. Barakaldo (Vizcaya). España

** Sección de Imagen Cardíaca. Hospital Universitario de Cruces. Barakaldo (Vizcaya). España

*** Servicio de Anatomía Patológica. Hospital Universitario de Cruces. Barakaldo (Vizcaya). España

\section{Recibido: 07/09/2020}

Aceptado: 10/10/2020

En línea: 31/12/2020

\section{Correspondencia}

José David Rodrigo Carbonero

jdavidrodrigo@gmail.com

Citar como: Beteré Reynolds J, Rodríguez Torres I, Rodrigo Carbonero JD, Pérez Rodrigo P, Díaz de Lezcano I. Diagnóstico incidental en tiempos de coronavirus: mixoma cardíaco en orejuela izquierda. Rev Ecocar Pract (RETIC). 2020 (Dic); 3 (3): 33-35. doi: 10.37615/retic.v3n3a13.

Cite this as: Beteré Reynolds J, Rodríguez Torres I, Rodrigo Carbonero JD, Pérez Rodrigo P, Díaz de Lezcano I. Incidental diagnosis in coronavirus times: cardiac myxoma in the left atrial appendage. Rev Ecocar Pract (RETIC). 2020 (Dic); 3 (3): 33-35. doi: 10.37615/retic.v3n3a13.

\section{Palabras clave \\ $\triangleright$ Mixoma \\ $\triangleright$ Coronavirus \\ $\triangleright$ COVID-19 \\ $\triangleright$ Tumor cardíaco}

\begin{tabular}{l}
\hline Keywords \\
\hline$\triangleright$ Myxoma \\
$\triangleright$ Coronavirus \\
$\triangleright$ COVID-19 \\
$\triangleright$ Cardiac mass \\
\hline
\end{tabular}

\section{RESUMEN}

El mixoma cardíaco es el tumor primario benigno intracardíaco más frecuente. Su localización típica la encontramos en la aurícula izquierda, adherido al septo interauricular. La ecocardiografía es su principal método diagnóstico. Se presenta el caso de un mixoma cardíaco que, como peculiaridades, tiene en primer lugar una localización atípica, al situarse en la orejuela izquierda; y, en segundo lugar, que se diagnosticó a partir del hallazgo accidental de una masa auricular en una TC solicitada en nuestro Servicio de Urgencias como aplicación directa del protocolo sobre "Manejo de los pacientes bajo sospecha de COVID-19".

ABSTRACT
Cardiac myxoma is the most common primary intracardiac benign tumour. Left atrium is the most frequent lo-
cation, right next to the interatrium septum. Echocardiography is the technique of choice for detecting myxoma.
We present a case which peculiarity is the atypical location of the mass in the left appendage and the diagnosis as
an incidental finding in a CT scan as part of the "Management of patients under suspicion of COVID-19" protocol.

\section{Presentación de caso}

La actual pandemia por SARS-CoV-2 ha dado pie a que se generen situaciones clínicas poco frecuentes. A continuación, se expone un caso clínico representativo de esta nueva problemática.

Se presenta el caso de un hombre de 69 años con antecedentes de hipertensión arterial y asma persistente leve que acudió al Servicio de Urgencias por un cuadro de fiebre termometrada de hasta $38^{\circ} \mathrm{C}$ y disnea de 5 días de evolución. A la exploración física se encontraba hemodinámicamente estable, con $\mathrm{SatO}_{2}$ 97\% aire ambiente y afebril. A la auscultación pulmonar, destacaban roncus y sibilantes dispersos, siendo el resto de la exploración anodina. Ante la gravedad de la pandemia actual de COVID-19, siguiendo el protocolo existente en nuestro centro, se pidieron las siguientes pruebas complementarias: frotis nasofaríngeo con PCR de coronavirus, electrocardiograma, radiografía de tórax y analítica de sangre, siendo todas estas pruebas anodinas, salvo una elevación significativa de dímero $D$.

Dada la elevación del dímero $\mathrm{D}$, se decidió ampliar el estudio diagnóstico dentro del protocolo de cribado de COVID-19 y se solicitó angiotomografía computarizada (angio-TC) con protocolo de Triple Rule Out para descartar la presencia de tromboembolismo pulmonar (TEP). En este estudio, se descartó la presencia de TEP, pero se describió como hallazgo casual una imagen nodular en la aurícula izquierda de $24 \times 22 \mathrm{~mm}$ (Figura 1 y Figura 2).

Finalmente, la PCR para coronavirus fue negativa y, con los hallazgos de la TC, se decidió el ingreso en la planta de Cardiología para el estudio de la masa de la aurícula izquierda. Durante su estancia en planta, el paciente permaneció asintomático, con mejoría de su clínica respiratoria con tratamiento broncodilatador. Se realizaron ecocardiografías transtorácica (ETT) y transesofágica (ETE), que confirmaron la presencia de una masa anclada en la pared libre lateral de la aurícula izquierda próxima a la comisura lateral mitral, la orejuela izquierda y el anillo posterolateral mitral, de $28 \times 23 \mathrm{~mm}$, considerándose el mixoma auricular como primera posibilidad diagnóstica (Vídeo 1 a Vídeo 3). Con este diagnóstico preliminar, se presentó el caso en sesión conjunta médico-quirúrgica y se decidió tratar de forma quirúrgica durante el ingreso. Finalmente, se realizó la intervención mediante esternotomía parcial y tumorectomía con resección endocárdica con posterior plastia. La masa obtenida se envió a Anatomía Patológica, donde se confirmó el diagnóstico (Figura 3 y Figura 4). El posoperatorio fue favorable, por lo que el paciente pudo ser dado de alta. 


\section{Estudio por imagen}

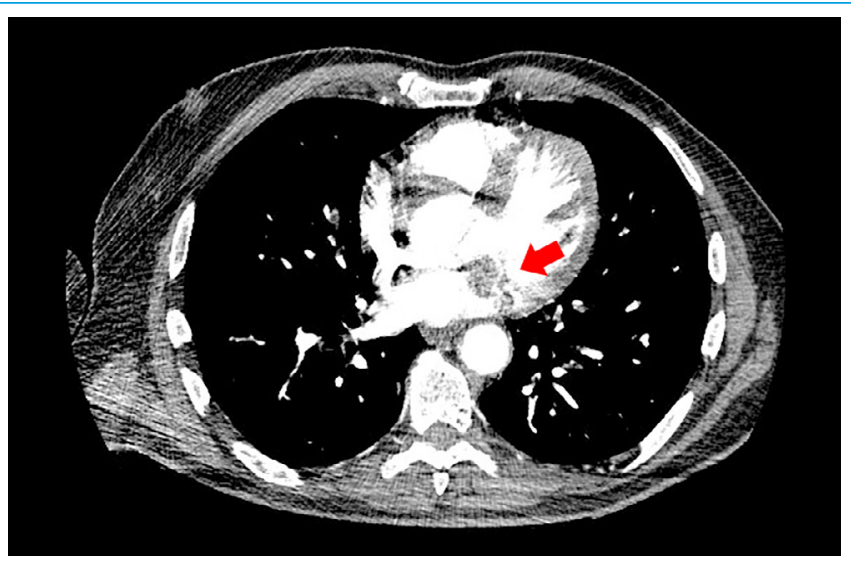

Figura 1. Cardio-TC, imagen axial. Se aprecia una imagen nodular en aurícula izquierda de $24 \times 22 \mathrm{~mm}$

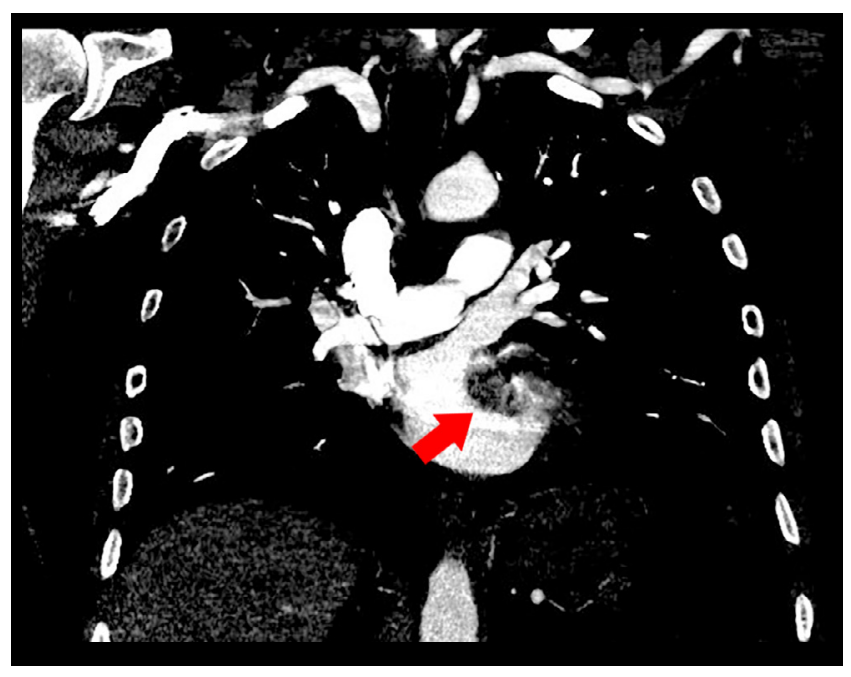

Figura 2. Cardio-TC, imagen coronal. Se ve la masa en la pared de la aurícula izquierda

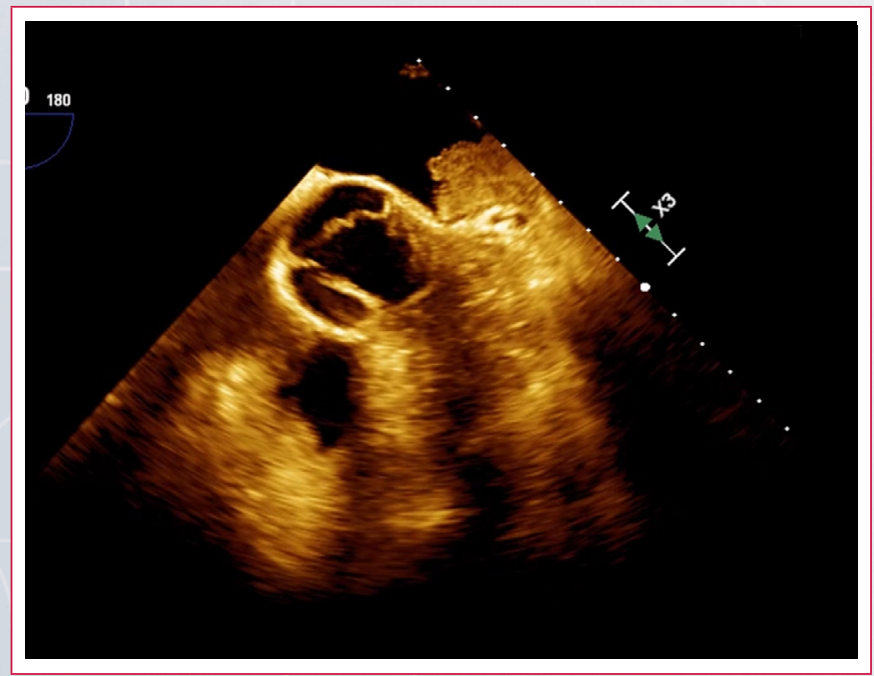

Vídeo 1. ETE a nivel medioesofágico con barrido de imagen que muestra una masa de $3 \times 3 \mathrm{~cm}$ con base de anclaje amplia en pared libre lateral de aurícula izquierda próximo a comisura lateral y orejuela izquierda

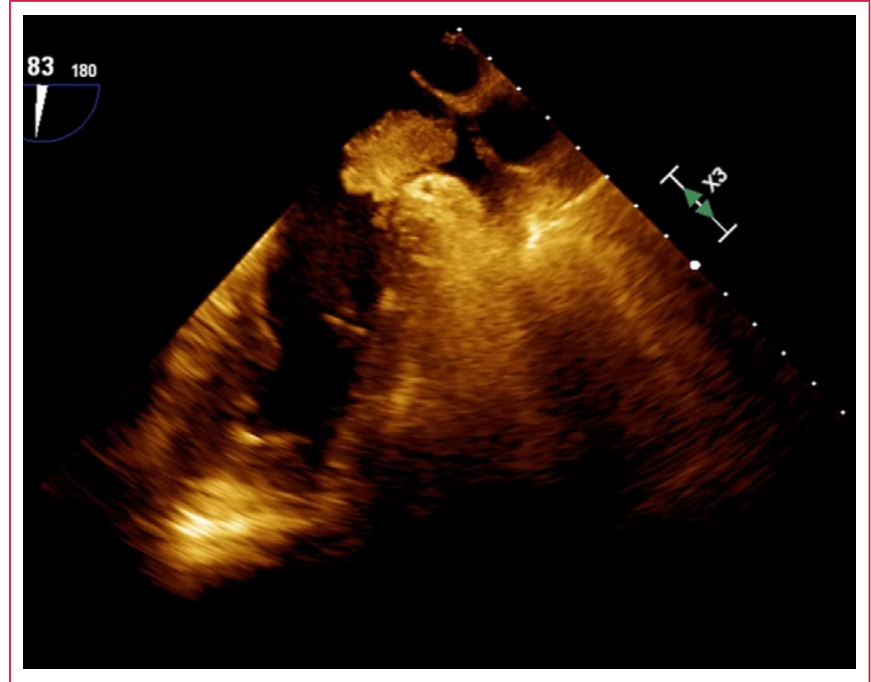

Vídeo 2. ETE a nivel medioesofágico en plano de $80^{\circ}$ que muestra la masa localizada en la pared libre de la aurícula izquierda cerca de la orejuela izquierda

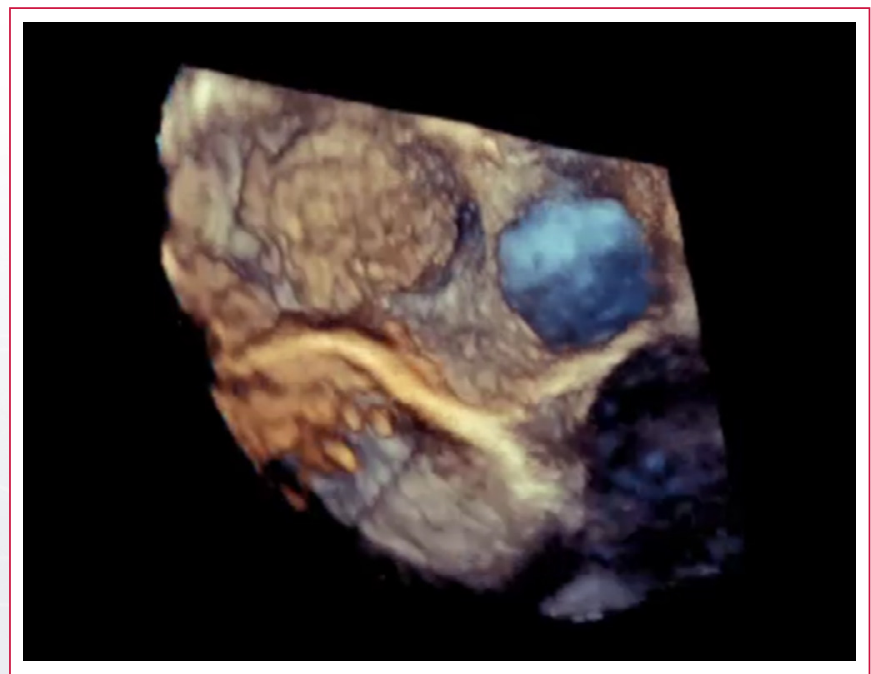

Vídeo 3. Reconstrucción en ETE 3D de la masa que se sitúa por delante de la orejuela izquierda

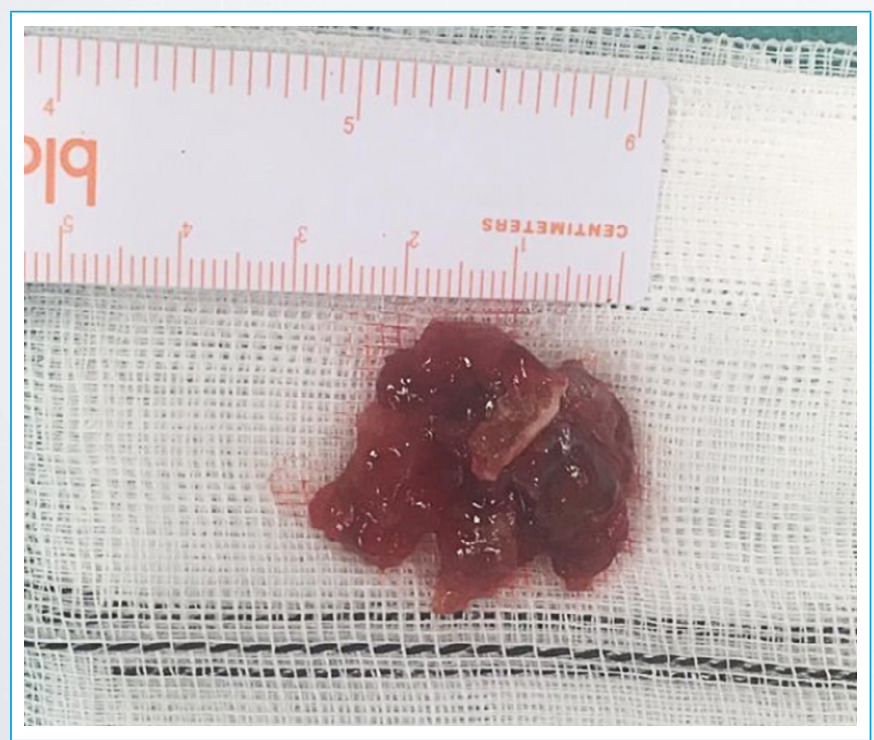

Figura 3. Aspecto macroscópico de la masa extraída quirúrgicamente 


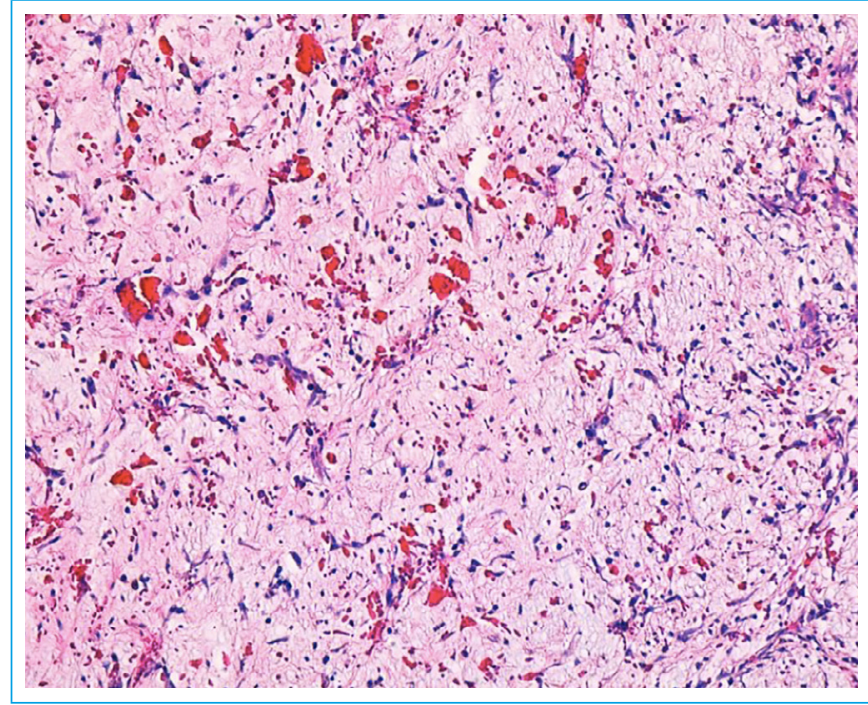

Figura 4. Imagen del estudio microscópico de la masa que confirma el diagnóstico de mixoma cardíaco

\section{Discusión}

Los tumores primarios del corazón son entidades muy poco frecuentes. En las distintas series en las que se analizan necropsias de poblaciones no seleccionadas, la incidencia varía entre un 0,0017 y un 0,03\%. Dentro del subgrupo de los tumores cardíacos primarios, tres cuartas partes son benignos, y aproximadamente la mitad de ellos son mixomas; la otra mitad corresponde a lipomas, rabdomiomas, fibroelastomas y otras variedades menos frecuentes. Son mucho más frecuentes entre los 30-60 años, siendo más habituales en mujeres (3:1). La localización más frecuente la encontramos dentro de la aurícula izquierda, en el septo interauricular, y más específicamente la zona de la fosa oval(1). Como particularidad que se ha de destacar, el mixoma de nuestro caso tenía una localización atípica, al estar adherido a la pared lateral de la aurícula izquierda ocupando parte de la orejuela izquierda.

Las formas de presentación clínica de estos tumores, y en particular de los mixomas, son diversas y dependen básicamente de su tamaño y localización. Dentro del espectro clínico que pueden causar, la tríada clásica consiste en síntomas generales, embolizaciones a distancia y sintomatología obstructiva simulando una patología valvular(2).

La ecocardiografía en sus distintas modalidades se alza como el método diagnóstico de elección, ya que es una herramienta no invasiva y de bajo coste que permite obtener información detallada sobre la orientación espacial exacta del tumor y su repercusión hemodinámica. La TC y la resonancia magnética nuclear aportan información complementaria valiosa. Una vez detectados por imagen, el diagnóstico de confirmación de estos tumores se obtiene con la anatomía patológica ${ }^{(2)}$.

En el diagnóstico diferencial del caso expuesto, se desestimó un trombo como primera posibilidad, debido a que el paciente no tenía factores de riesgo protrombóticos y a que se descartó la infección por COVID-19 (enfermedad que se está viendo que tiene alta capacidad protrombótica). En cuanto a la endocarditis, ésta suelen asentar en el tejido endocárdico valvular y ser más pequeña y móvil. Por otro lado, la densidad ecocardiográfica de nuestro hallazgo descartaba que se tratara de una lesión calcificada. Por tanto, se planteó el tumor como primera posibilidad diagnóstica y, dado que el paciente no presentaba neoplasias primarias a otros niveles y que la masa asentaba sobre la aurícula izquierda, fue el mixoma el que se postuló como primera posibilidad diagnóstica.

El tratamiento de elección es la extirpación quirúrgica, que ha de ser precoz, y es curativa en la mayoría de los pacientes, con un excelente pronóstico a largo plazo. La recurrencia puede considerarse rara, ya que es del 1-5\% según las diferentes series.

\section{Conclusión}

El incremento en el uso de las técnicas de imagen por todo tipo de causas está haciendo que sea relativamente frecuente encontrar lesiones cardíacas como un hallazgo incidental en la ecocardiografía 2D o en una imagen de TC.

Las masas cardíacas plantean un amplio diagnóstico diferencial, dentro del cual se incluyen tumores, vegetaciones, trombos, lesiones calcificadas y algunas variantes de la normalidad, de ahí que sus características morfológicas obtenidas en las pruebas de imagen, apoyadas junto con el contexto clínico del paciente, sean clave a la hora de dar un diagnóstico concreto, ya que el manejo terapéutico de las masas cardíacas puede ser muy distinto en función de su etiología.

El caso que presentamos constituye un claro ejemplo ilustrativo de lo expuesto previamente. Se trata de un paciente que acudió al Servicio de Urgencias por una infección respiratoria, en el que se llega al diagnóstico de un mixoma partiendo del hallazgo accidental de una masa auricular en una TC. Cabe destacar que la indicación de realizar esta TC en el paciente expuesto surgió de la aplicación directa del protocolo sobre "Manejo de los pacientes bajo sospecha de COVID-19" que se desarrolló para el Servicio de Urgencias de nuestro centro, con motivo de la pandemia actual por COVID-19.

\section{Ideas para recordar}

- El mixoma cardíaco es el tumor primario benigno intracardíaco más frecuente, siendo su localización típica la aurícula izquierda. La ecocardiografía es su principal método diagnóstico y la extirpación quirúrgica su tratamiento de elección.

- El uso cada vez más estandarizado de la TC y la ecocardiografía 2D en la práctica clínica diaria ha dado pie a cada vez más incidentalomas cardíacos.

- El diagnóstico diferencial del incidentaloma cardíaco es de vital importancia ya que el manejo terapéutico de sus distintas etiologías es muy diferente. Éste debe basarse en las características morfológicas de la masa obtenidas en las pruebas de imagen, apoyadas junto con el contexto clínico del paciente.

- En este caso, la aplicación sistemática del protocolo de SARS-CoV-2 en nuestro centro sanitario ha supuesto el diagnóstico y tratamiento precoz de un mixoma cardíaco en un paciente asintomático adelantándonos al desarrollo de sus complicaciones.

\section{Bibliografía}

1. Marchena Yglesias P, et al. Mixoma auricular izquierdo como forma de presentación de una angina de esfuerzo. An Med Interna (Madrid) 2006; 23 (6): 279-281.

2. Mendoza-Chuctaya G y Montesinos Cárdenas A. Insuficiencia cardíaca por mixoma auricular izquierdo gigante: reporte de un caso. Horiz Med 2017; 17 (1): $72-75$. 